\title{
OBITUARY
}

\section{DR. CHEVALIER JACKSON}

IT is fitting that an obituary notice of Dr. Chevalier Jackson, who died on I6th August, at the advanced age of ninety-two, should take the form of personal memories, rather than that of a formal curriculum vitae.

In I923 Sir StClair Thomson urged me to visit Philadelphia and to apply for a place in one of the courses of instruction given there; he impressed on me the necessity of avoiding delay, for the reason that Dr. Jackson's health was somewhat fragile and that he might consequently have to abandon his teaching activities. I had just previously met Dr. Gabriel Tucker, his warm hearted and energetic associate, who told me of Dr. Jackson's early struggles in Pittsburg, where he attempted to establish as a speciality the art and science of Bronchoscopy and Esophagoscopy, apparently under financial embarrassment.

As a young and ignorant clinical assistant I was successful in obtaining a place in his course in the summer of I923; my reception was most cordial and Dr. Jackson had gone so far as to take a room for me at one of the clubs and to instruct them to send the account to him, an act of generosity which I was naturally unable to accept, but which impressed me deeply.

I was not the first from England to visit him, for as far back as Igr $3 \mathrm{Mr}$. Howarth had paid a visit to him at Pittsburgh.

The experiences gained in this Summer Course have served me to the greatest advantage throughout my medical life and very many of my friends and colleagues in the British Isles owe a similar debt of gratitude to this great man.

Fragile as he was in physique, yet his energy was enormous, and even in the two days of each week which he spent in bed, to conserve his strength, were occupied in the practice of endoscopic procedures, as well as in writing.

At that time the removal of foreign bodies from the air and food passages owed its elaboration to the investigations of laryngologists, among whom Jackson was one of the early pioneers; as I said at the time, in writing a short account of the course, hours and even days were spent in preparation and planning and minutes or even seconds in the removal of foreign bodies, so skilful was his wizardry, as MacKenty of New York described it.

But of greater benefit to medicine as a whole were his researches and descriptions of the physiology and pathology of the air passages, of the lungs, and of the cesophagus; direct examination enabled him to interpret the mechanisms in question and to explain the opening and closure of the bronchi, the reasons for physical signs and also the control of the mouth of the oesophagus.

Chevalier Jackson was born at Pittsburgh in 1865 and qualified as M.D. at Jefferson Medical College, Philadelphia in I886, at the early age of $2 \mathrm{I}$; he 


\section{Obituary}

practised medicine in Pittsburgh and was elected Professor of Laryngology there in Igr2; the struggle must have been hard and in I9I6 he returned to his Alma Mater, where he became Professor of Laryngology. Subsequently, in I924, a chair of Bronchoscopy and Esophagoscopy was created for him. $\mathrm{He}$ was also professor of Bronchoscopy and Esophagoscopy in the University of Pennsylvania, a post especially instituted for him; I well remember the rush from one hospital to the other with a rapid lunch in a Cafeteria in the company of Gabriel Tucker and the genial Louis Clerf.

As many know a special clinic was later established in Temple University, where his son well-known to many as C.L., reigns today.

Chevalier Jackson was a founder of the America College of Surgeons, and in this he showed the breadth of his outlook, as in many other directions connected with the wider aspects of Medicine and Surgery.

He was Officer of the Legion of Honour and Laureate of the Academie de Medicine of Paris, in addition to innumerable other distinctions; of especial interest to us were his election as honorary Fellow of the Royal Society of Medicine of London, honorary member of the Scottish Society of Otology and Laryngology and Honorary Fellow of the Royal College of Surgeons of Edinburgh, an honour conveyed to him by his son in his absence, at the time of the International Congress of 1949 .

A distinction which must have given him pleasure was the receipt of the Medallion of the American College of Chest Physicians in 1952, in recognition of his services to general medicine; he must also have been gratified to be appointed as Doctor of Humane Letters at Jefferson Medical College.

So passes a great man and so ends an epoch; thoracic medicine and surgery have advanced to an extraordinary degree and the art and science of these branches is wide-spread beyond the field of the laryngologist and early endoscopist. No greater memorial could remain than the recognition by the Medical profession in many countries of the immeasurable possibilities unfolded by this pioneer and by the untold benefits resulting from his teaching and example.

V. E. Negus. 